\title{
Cáncer de ovario: rastrear o no rastrear, esa es la cuestión
}

Jacobs I, Skates S, et al. Screening for ovarian cancer: a pilot randomized control trial. Lancet 1999; 353:1207-1210

\author{
Objetivo \\ Evaluar el valor de un rastreo secuencial de cáncer de ovario ( $\mathrm{Ca} 0$ ) con \\ CA125 y ecografía abdominal.
}

\section{Diseño}

Estudio randomizado y controlado.

\author{
Lugar \\ Instituto Nacional de Salud, Reino Unido.
}

\section{Pacientes}

Se aleatorizaron 22000 mujeres post-menopáusicas mayores de 45 años, sin historia de $\mathrm{Ca} 0$ que habían participado previamente en un estudio de rastreo: 10997 fueron asignadas al rastreo y 10958 a vigilancia sin rastreo.

\section{Intervención}

El rastreo se realizaba por tres años, y consistía en el dosaje en sangre, del marcador tumoral CA125 tres veces por año; si este resultaba mayor - igual a $30 \mathrm{U} / \mathrm{mL}$ se realizaba una ecografía. La ecografía medía volumen y morfología de los ovarios, si el primero era mayor de $8,8 \mathrm{ml}$, se consideraba anormal, y se derivaban para una investigación quirúrgica. Si el tamaño era normal pero la morfología alterada, se consideraba dudosa y se reevaluaba con ecografía transvaginal cada tres meses por el lapso de un año. Se realizó un seguimiento de 7 años.

\section{Medición de resultados principales}

Incidencia de $\mathrm{Ca} 0$ en ambos grupos. Se consideraba rastreo positivo a las mujeres que se sometían a una intervención quirúrgica por sospe- cha de $\mathrm{CaO}$, verdaderos positivos si resultaban tener $\mathrm{CaO}$ y falsos positivos a los rastreos positivos que no tenían cáncer. Se midió sobrevida y mortalidad total.

\section{Resultados principales}

El 70\% de las pacientes cumplieron los 3 años de rastreo, un $85 \%$ lo hizo por lo menos un año. En el grupo rastreo se realizaron 781 ecografías a 468 mujeres con CA125 elevado, de las cuales 29 merecieron investigación quirúrgica. De las 29 mencionadas, 6 tenían un Ca0 y 23 fueron falsos positivos asociados a tumores benignos (VPP* de la indicación quirúrgica $=20 \%$ ). Durante el seguimiento de este grupo, 10 pacientes más desarrollaron $\mathrm{CaO}$, sin mediar la intervención del rastreo. En el grupo control, se diagnosticaron durante el seguimiento $20 \mathrm{CaO}$.

\begin{tabular}{l|l|l|l|l}
\hline & Ca0 & NoCao & Total & \\
\hline Rastreo & 16 & 10981 & 10997 & \\
\hline No Rast & 20 & 10938 & 10958 & \\
\hline Total & 36 & 21919 & 21955 & \\
\hline
\end{tabular}

La sobrevida de los pacientes con cáncer fue mayor en el grupo rastreo que en el control, ( 72,9 meses y 41,8 meses respectivamente) pero no hubo diferencia estadísticamente significativa en la mortalidad (18 en el grupo control y 9 en el rastreo, RR= 2 IC95\% 0,78-5,13). Los cánceres detectados en el grupo rastreo fueron de menor grado comparados con los del control, sin diferencias con respecto al estadío.

\section{Conclusiones}

Resulta justificable y factible realizar un ensayo clínico controlado más grande empleando una técnica secuencial con marcadores tumorales y ecografía, para evaluar si el rastreo disminuye la mortalidad.

Fuente de financiamiento: Instituto Nacional de Salud, Reino Unido.

\section{COMENTARIO}

El CaO representa la mortalidad más elevada de los cánceres ginecológicos y es responsable del 4-5\% de las muertes en mujeres mayores de 60 años. Menos del 30\% de los cánceres diagnosticados están inicialmente Limitados al ovario, el resto ya presenta diseminación metastática. El rastreo de Ca0 resulta atractivo ya que si bien la tasa global de sobrevida a los 5 años es menor al 25\%, si es descubierto en estadíos tempranos supera el $90 \% 1$. De acuerdo a los criterios de Frame y Carlson para rastreo, tiene un período asintomático largo y un tratamiento efectivo en los estadíos iniciales, sin embargo es poco prevalente y las técnicas para diagnosticarlo están sujetas a controversia en cuanto a efectividad y costo ${ }^{2}$. El presente trabajo si bien está diseñado como un estudio piloto para evaluar la factibilidad de un estudio más grande, permite extraer conclusiones que resultan trascendentes. Se necesita un enorme esfuerzo de rastreo para poder detectar cánceres de ovario temprano, ya que la incidencia es muy baja (16/10000 en 7 años de seguimiento). En el estudio la diferencia no fue significativa y si bien es verdad que la sobrevida fue mayor para el grupo rastreo, en términos poblacionales esta es nimia y puede deberse al azar $y / 0$ a sesgo de anticipación. * Los autores refieren que para poder hacer un estudio que pueda evaluar disminución de la mortalidad, con un poder de mortalidad del $80 \%$, van a necesitar 120000

*Ver glosario

\#Datos calculados por el comité editorial

\section{Dr. Augusto Granel}

Unidad de Medicina Familiar y Preventiva. Hospital Italiano de Buenos Aires. pacientes y 6 años de seguimiento. ¿Esto realmente se justifica? Los autores reportan que el valor predictivo positivo* es del 20\%, sin embargo esto es falaz, porque está calculado sobre los pacientes enviados a investigación quirúrgica y en realidad debería hacerse sobre todos los que tienen un CA125 elevado que es el primer paso del rastreo. El valor predictivo positivo* sería en este caso de solo $1,2 \%$, debiendo siempre considerarse el perjuicio generado a los pacientes por los resultados falsos positivos. Los beneficios del rastreo no están claros. Las mujeres en las que el rastreo por CA125 y ecografía son positivas, deben someterse a una Laparotomía en que de cinco cirugías una mostraría un cáncer. Otro aspecto es la complejidad del rastreo que pone en serias dudas su factibilidad, tres extracciones de sangre anuales y eventualmente ecografías periódicas. Si bien en el estudio hubo un alto cumpliento, la población elegida era muy seleccionada ya que fue extraida de una muestra utilizada anteriormente por los autores. Los datos de este primer estudio randomizado apoyan las recomendaciones de no hacer rastreo de $\mathrm{CaO}^{3}$. La decisión debe considerar una evaluación individual del riesgo, teniendo en cuenta que este aumenta significativamente con la historia de $\mathrm{CaO}$ en la familia (aumenta tres veces con un familiar de primer grado afectado), y disminuye con el número de embarazos y el uso de anticonceptivos orales. ${ }^{4}$

\section{Referencias}

1. Young RC, Walton LA, Ellenberg SS, et al. Adjuvant therapy in stage I and stage II epithelial ovarian cancer. N. Engl. J. Med. 1990; 322: 1021-27

2. Van Nagell JR, Gallion HH, Pavlik EJ. Ovarian cancer screening. Cancer 1995; 76:2086-91

3. American College of Physicians. Screening for Ovarian Cancer: Recommendations and rationale. Ann. Intern. Med. 1994; 121: 141-42

4. Kerlikowse K, Brown JS, Grady DG. Should women with familial ovarian cancer undergo prophylactic oophorectomy? 0bstet Gynecol 1992; 80:700-707 